\title{
Minining
}

http://dx.doi.org/10.1590/0370-44672015710008

Tulio Viegas Bicalho Resende

Engenheiro Químico, M. Sc. em Engenharia Mineral Faculdade Pitágoras

Curso de Engenharia de Minas

Belo Horizonte - Minas Gerais - Brasil

tulioviegas@gmail.com

José Aurélio Medeiros da Luz

http://orcid.org/0000-0002-7952-2439

Professor Associado

Universidade Federal de Ouro Preto - UFOP

Escola de Minas

Departamento de Engenharia de Minas

Ouro Preto - Minas Gerais - Brasil

jaurelioluz@yahoo.com

\section{Error variance of short duration sieving}

\begin{abstract}
In this study, the variance of ordinary sieving test error was determined concerning the specification limit of sized iron ore product by subtracting the fundamental error (described by the Gy's formalism for sampling), from the global error (recoverable from database of historical values). The results allowed the calculation of the confidence interval for the percentage of material finer than the upper screen specification limit. Thereafter, a method to estimate the so-called effectiveness coefficient of the screening operation was developed, which is the ratio between number of particle presentations to passage and the number of oscillations during the material shaking on the screen surface. This estimation was based on the probability statements and particle size distribution of the feed. Considering the size distribution of the products tested in this study, the results have shown that the sieving time could be reduced when determining the percentage of material finer than the upper specification mesh.
\end{abstract}

Keywords: screening, sampling theory, Gy's formalism, iron ore.

\section{Introduction}

A check routine for the accuracy and precision of the methods used in the selection, preparation and testing of particulates is required to ensure representative samples for an industrial quality control. The sieving process is distinguished by an easier detection of sampling bias (Gy, 1992). This feature makes it a checker for sampling accuracy, since the sieving

\section{Literature review}

A batch $L$ is homogeneous when the proportion of a component of interest $\mathrm{a}_{\mathrm{L}}$ is distributed according to a perfect uniform distribution. It means that for every

$$
h_{i}=\frac{\left(a_{i}-a_{L}\right)}{a_{L}} \frac{M_{i}}{M_{\bar{l}}}=N_{F} \frac{\left(a_{i}-a_{L}\right)}{a_{L}} \frac{M_{i}}{M_{L}}
$$

This definition takes into account the mass of the fragments; therefore those

$$
\sigma^{2}\left(h_{i}\right)=\frac{1}{N_{F}} \sum_{i} h_{i}^{2}=N_{F} \sum_{i}\left[\frac{\left(a_{i}-a_{L}\right)}{a_{L}}\right]^{2}\left[\frac{M_{i}}{M_{L}}\right]^{2}
$$

where $i=1,2,3 \ldots N_{F}$.

The formula for the constitutional heterogeneity applies only to an isolated finite population of units standard procedure could be controlled and the sieving test error is known from a plant history basis.

Grigorieff et al. (2004) studied the influence of the preparation protocols on the global estimation error. The authors compared some preparation protocols by measuring the ash content of pairs of coal samples obtained from the splitting of global samples. By this method, the difference in chemical analysis (statistical deviation) was approximated to the accuracy of the global estimation error. Considering that for sieving there is no comminution, the technique could be adapted for estimating the variance of the sieving test error and guarantee its role in ensuring sampling quality. that are heavier have more influence on heterogeneity than the lighter ones. The and the content of the critical component is $a_{L}$, then the contribution of each individual fragment $i$ to heterogeneity $h_{i}$ is expressed by the following equation (Pitard, 1993):
$U_{u}$. It means that the calculation requires the knowledge of the total number of fragments in the batch never determined in practice. As an approximation, we use the constant factor of constitution heterogeneity, $H I_{L}$, which is independent of the lot size (Pitard, 1993): 
$H I_{L}=C H_{L} M_{\bar{\imath}}=\sum_{i}\left[\frac{\left(a_{i}-a_{L}\right)}{a_{L}}\right]^{2}\left[\frac{M_{i}^{2}}{M_{L}}\right]$

The constant "factor of constitution heterogeneity, $H I_{L}$ of a particular size class

Where: $M_{C}$ is the mass of the average fragment of the size class whose invariant heterogeneity is to be estimated;

$a_{c}$ is the proportion of the size class of interest;

Where, fis the dimensionless shape factor, accepted around 0.5 (for this material);

$\rho$ is the average true density of the material $\left[\mathrm{kg} / \mathrm{m}^{3}\right]$;

$d_{C}$ is the average particle size of the size class whose invariant heterogeneity is

If the selecting probability $\mathrm{P}$ is valid for an individual particle, the rela- of interest is calculated by the following approximation (Gy, 1992):

$$
H I_{L} \approx \frac{\left(1-2 a_{c}\right)}{2 a_{c}} M_{C}+\sum_{k} M_{k} a_{k}
$$

$k$ is the representation of each size class of the average fragment that characterizes the particle size distribution of the product;

$F_{k}$ is the average fragment of each size class k;

$$
\mathrm{M}_{\mathrm{c}}=f \rho d_{c}^{3} \quad \mathrm{M}_{\mathrm{k}}=f \rho d_{k}^{3}
$$

to be estimated;

$d_{k}$ is the average particle size of each size class $\mathrm{k}$.

The fundamental sampling error $F S E$ is defined as the one that occurs when the perfect sampling requirements

$$
\sigma^{2}(F S E)=\frac{1-P}{P M_{L}} H I_{L}
$$

tionship $M_{s}=P M_{L}$ is met, and this implies the following relationship:

$$
\sigma^{2}(F S E)=\left(\frac{1}{M_{S}}-\frac{1}{M_{L}}\right) H I_{L}
$$

Where $M_{s}$ is the sample mass or an intermediate portion selected at any step of a sampling protocol and $M_{L}$ is the lot mass or that one of an immediately preceding step in which the mass $M_{S}$ was extracted.

From the replacement of invariant heterogeneity for a particular size
$M_{\text {r }}$ is the mass of the average fragment of each size class k;

$a_{k}$ is the proportion of each size class.

In addition, the following equations hold:

are met; it is generated only by the constitutional heterogeneity (Gy, 2004). Considering a uniform probability $P$ of selecting the fragments, the variance of the fundamental sampling error can be expressed as:

$$
\sigma^{2}(F S E)=\left[\frac{1}{M_{s}}-\frac{1}{M_{L}}\right]\left[\frac{\left(1-2 a_{c}\right)}{2 a_{c}} M_{c}+\sum_{k} M_{k} a_{k}\right]
$$

According to Gy (1992), the relative difference between the critical content, $a_{s}$, of the sample and that one of the sampled lot, $a_{L}$, is represented

\section{Process variability}

The overall variability of an industrial process comprises the instantaneous by the relative sampling error (TSE). Whilst the relative difference between the analytical result $a_{R}$ and the content $a_{L}$ is denoted by the total analytical er-

$$
\sigma^{2}(G E E)=\sigma^{2}(F S E)+\sigma^{2}(T A E)
$$

variability and that one resulting from the quality shifts over time. Under these ror $(T A E)$. The global estimation error is met when considering those errors as stochastically independent:

aspects, the overall variation of a process is represented by:

$$
\sigma^{2} \text { (overall) }=\sigma^{2} \text { (within subgroups) }+\sigma^{2} \text { (between subgroups) }
$$

The first term of the last equation is obtained by taking samples within subgroups with the interval between them close to zero. The second varia- tion term is obtained by measuring the dispersion between the subgroups.

Then, the variance within the subgroups can be estimated from the average range $\bar{R}$ of the subgroups members by the following unbiased estimator (Montgomery and Runger, 2011):

$$
\sigma^{2} \text { (within subgroups) }=\left(\frac{\bar{R}}{d_{2}}\right)^{2}
$$


Where the constant $d_{2}$ is tabulated for various sample sizes (for subgroup of size two, $\left.1 / d_{2}=0.886\right)$.

According to the method used by
Grigorieff et al. (2004), the global estimation error can be approximated by sampling ranges, since only Gaussian stochastic variability occurs. From the replacement of the global estimation error by the within subgroup variance, the overall analysis error is determined by the following:

$$
\sigma^{2}(T A E)=\left(\frac{0.886 x \bar{R}}{a_{L}}\right)^{2}-\left[\frac{1}{M_{s}}-\frac{1}{M_{L}}\right]\left[\frac{\left(1-2 a_{c}\right)}{2 a_{c}} M_{c}+\sum_{k} M_{k} a_{k}\right]
$$

As an additional remark, it is noteworthy that although it is widely used, Gy's formalism is based on generalized indices (and therefore approximate),

\section{Likelihood of passage in screening}

The probability of a fragment of size $d$ passing through a mesh sieve of aperture $a$ is always less than unity, as the lower the relationship $(\boldsymbol{a}-\boldsymbol{d})$, the lower that probability is (Gy, 1992). However there are fragments, approximate to the nominal size of the

Where $\varphi$ is the wire thickness, $\boldsymbol{a}$ is the mesh aperture and $\boldsymbol{d}$ is the particle di-

Where $p_{1}$ is the probability of passing through the screen with a single presentation.

\section{Law of total probability}

Considering $\boldsymbol{A}_{1}, \boldsymbol{A}_{2} \ldots \boldsymbol{A}_{n}$ as mutually exclusive events and $\boldsymbol{P}\left(\boldsymbol{B} \mid \boldsymbol{A}_{n}\right)$ an arbitrary not explicitly taking into account the actual features of the material under analysis. To tackle this drawback, the use of protocols that lead to the

aperture size $\boldsymbol{d} \approx \boldsymbol{a}$, that can both be retained or pass through the screen. At a hypothetical experiment in which the assay material was repeatedly sieved, the same fragments could be either retained or passed through the mesh, since the probability of passage at

$$
p_{1}=\left(\frac{a-d}{a+\varphi}\right)^{2}
$$

ameter.

The probability $\boldsymbol{p}_{\boldsymbol{n}}$ of passage for $\boldsymbol{n}$

$$
p_{n}=1-\left(1-p_{1}\right)^{n}
$$

The number of presentations $(\boldsymbol{n})$ over the screen is a function of crowding and residence time, $\tau$, considering an effectiveness $\boldsymbol{y}$

$$
n=f \tau y
$$

event of the conditional probability of $\boldsymbol{B}$ assuming $\boldsymbol{A}_{n}$ then: calibration of the system under study is recommended. An example, applied to samples of bauxite, is developed by Bortoleto et al. (2014).

exactly the same point is infinitesimal.

The probability of an isolated spherical particle, with a single and orthogonal presentation, passing through the surface of an opening square screen was established by Gaudin (1975):

is calculated by the following equation:

of the operating frequency $\boldsymbol{f}$ (according to an approach developed by Carvalho \& Luz, 2005), as provided in the following equation:

$$
P(B)=\left[P\left(B \mid A_{1}\right) \cdot P\left(A_{1}\right)\right]+\left[P\left(B \mid A_{2}\right) \cdot P\left(A_{2}\right)\right]+\ldots+\left[P\left(B \mid A_{n}\right) \cdot P\left(A_{n}\right)\right]
$$

\section{Methods}

Figure 1

Average size distribution of the products sampled ( $\mathrm{Y}$ is the passing through fraction and $x$ is the mean class aperture; curves are Rosin-Rammler-Sperling-Benett distribution).

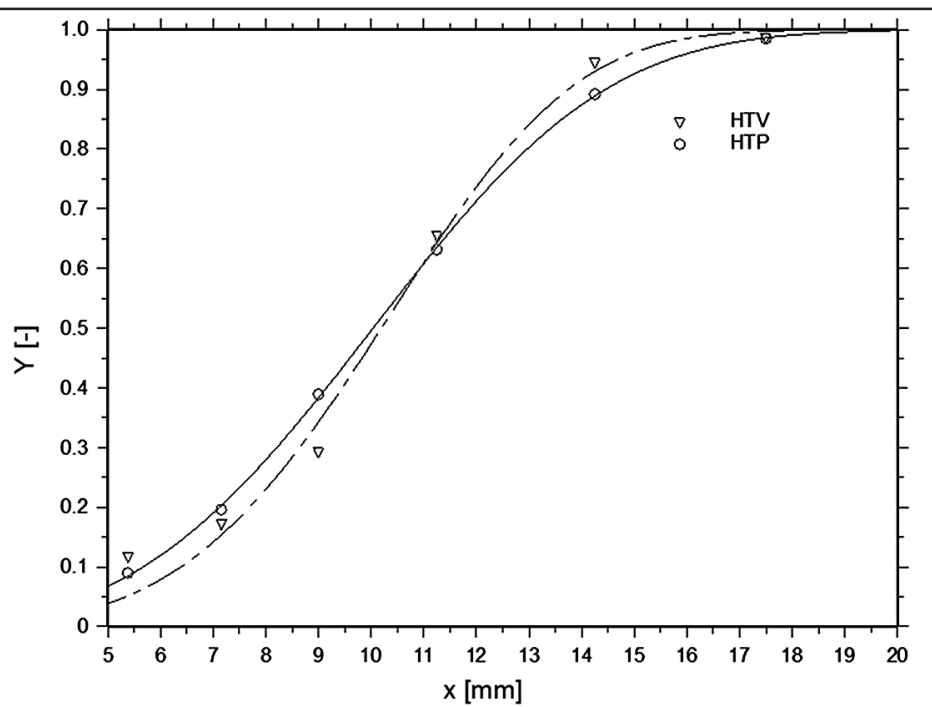

REM, Int. Eng. J., Ouro Preto, 71(2), 305-311, apr. jun. | 2018 
Two products processed at two typical iron ore processing plants, between September 2012 and September 2013, were sampled to have the error variance of their oversize fraction assayed in a sieving test. The sieve chosen was that concerning a $19.0 \mathrm{~mm}$ aperture, which is the upper specification limit and that one for which

In turn, Table 1 presents the size distribution parameter of those corre- the whole mass assayed had contact. It is observed in Figure 1 that the two products studied, named HTP and HTV, have a similar particle size distribution. Moreover these are also products whose quality remained stable during the increment collection period, meaning that the Pearson's coefficient of variation in production was

$$
Y=1-\mathrm{e}^{\left[\ln (0.5) \times\left(\frac{x}{x_{50}}\right)^{m}\right]}
$$

sponding equations for the two products (obtained by EasyPlot software package).

\begin{tabular}{c|c|c|c} 
Product & Median diameter $\left(\mathrm{x}_{50}\right)[\mathrm{mm}]$ & Sharpness index $(\mathrm{m})[-]$ & Coefficient of correlation[-] \\
\hline HTP & 12.804 & 4.1127 & 0.9915 \\
\hline HTV & 12.6148 & 3.4035 & 0.9988 \\
\hline
\end{tabular}

Linear samplers, which were set according to the parameters listed in Table 2, were used for the selection of forty global samples of $120 \mathrm{~kg}$. These were dried in thermal plates at a maximum temperature of

As shown in Table 3, the HTV's samples were first split into aliquots of $60 \mathrm{~kg}$ and then into the assay portions of $20 \mathrm{~kg}$, whereas the HTP's samples were divided from $60 \mathrm{~kg}$ into $18 \mathrm{~kg}$. After many prospective tests, in order to adjust the duration of the
$160{ }^{\circ} \mathrm{C}$ and split into samples $\boldsymbol{i}$ and $\boldsymbol{i}$, as shown in Figure 2. After that, mass reduction was determined to obtain the required amount so that the same variance of the fundamental sampling error was achieved. For the sampling

$$
\sigma^{2}(\mathrm{FSE})=\left[\sigma^{2}(\mathrm{FSE})_{1}+\sigma^{2}(\mathrm{FSE})_{2}\right]
$$

sieving operation, the effective experimental campaign was held at a square (500 mm x $500 \mathrm{~mm}$ ) automatic sieve with timer set to 5 minutes and shaking frequency of $20 \mathrm{~Hz}$, which means 6,000 vibrations. The screens frames (with 100 $\mathrm{mm}$ in height) were mounted in ascend- about $10 \%$ for the measurement of that retained in the $19.0 \mathrm{~mm}$ screen.

There are high correlation coefficients for Rosin-Rammler-Sperling-Bennett distributions which are displayed in Figure 1 and is expressed by the following equation:

Table 1

Distribution parameter of

Rosin-Rammler-Sperling-Bennett

distributions for the samples

preparation protocol, each change in mass was individually considered; therefore, the variance of the fundamental sampling error was obtained by summing the variance error at each step, as the following:

ing order of opening $6.3 \mathrm{~mm}, 8.0 \mathrm{~mm}$, $10.0 \mathrm{~mm}, 12.5 \mathrm{~mm}, 16.0 \mathrm{~mm}$ and 19.0 $\mathrm{mm}$. The experiments were carried out, registering the proportions of material retained at the $19.0 \mathrm{~mm}$ screen for samples $\boldsymbol{i}$ and $\boldsymbol{i}$, according to the flowchart of Figure 2.

\begin{tabular}{c|c|c|c|c|c|c} 
Product & $\begin{array}{c}\text { Number of } \\
\text { Increments }\end{array}$ & $\begin{array}{c}\text { Incremental } \\
\text { mass [kg] }\end{array}$ & $\begin{array}{c}\text { Sampling } \\
\text { mass }[\mathrm{kg}]\end{array}$ & $\begin{array}{c}\mathrm{Q} \\
{[\mathrm{ton} / \mathrm{h}]}\end{array}$ & $\begin{array}{c}\text { Sampler slots } \\
{[\mathrm{m}]}\end{array}$ & $\begin{array}{c}\text { Sampler } \\
\text { cutting } \\
\text { velocity } \\
{[\mathrm{m} / \mathrm{s}]}\end{array}$ \\
\hline HTP & 15 & 7.99 & 120 & 230.0 & 0.075 & 0.6 \\
\hline HTV & 14 & 8.68 & 120 & 250.0 & 0.075 & 0.6 \\
\hline
\end{tabular}

\begin{tabular}{c|c|c|c|c|c|c|c} 
Product & HIL $[\mathrm{kg}]$ & $\begin{array}{c}\text { Batch } \\
\text { mass }[\mathrm{kg}]\end{array}$ & MS1 $[\mathrm{kg}]$ & MS2[kg] & $\sigma^{2}(\mathrm{FSE}) 1$ & $\sigma^{2}(\mathrm{FSE}) 2$ & $\sigma^{2}(\mathrm{FSE})$ \\
\hline HTP & 0.632 & 120 & 60 & 18 & $5.27 \mathrm{E}-03$ & $2.46 \mathrm{E}-02$ & $3.0 \mathrm{E}-02$ \\
\hline HTV & 0.708 & 120 & 60 & 20 & $5.90 \mathrm{E}-03$ & $2.36 \mathrm{E}-02$ & $2.9 \mathrm{E}-02$ \\
\hline
\end{tabular}

Table 2

Samplers parameters obtained according ISO 3082.

Table 3

Required mass for an equal fundamental sampling error.

Figure 2

Flowchart of mass splitting procedure.
Sample mass reduction from $60 \mathrm{~kg}$ to $20 \mathrm{~kg}$ for HTP and $18 \mathrm{~kg}$ for HTV 
From the average range of the results of samples identified in the diagram of Figure 2 by $\boldsymbol{i}$ and $\boldsymbol{i i}$, the variance of the global estimation error $(0,886 \times \overline{\mathrm{R}})^{2} \mathrm{a}_{L}^{-2}$ was determined. The variance of the sieving test error of that retained in the $19.0 \mathrm{~mm}$ screen was calculated by subtraction of the variances of the global estimation error and the fundamental sampling error. The average percentage of material finer than
$19.0 \mathrm{~mm}$ was determined by the difference between $100 \%$ and the average percentage retained by the $19 \mathrm{~mm}$ screen. The confidence interval was calculated considering that the error follows normal distribution:

$$
L C I 95 \%=(100 \%-\text { expected value })+1.96 x \sqrt{s^{2}(T A E) a_{L}{ }^{2}}
$$

The passage probability through the $19.0 \mathrm{~mm}$ screen to the HTP and HTV was estimated by calculating the minimum number of presentations required for the sieving test. As such, the following approximations were done:

- the probability of passage through the $19.0 \mathrm{~mm}$ screen was considered as be- ing that determined by Gaudin's equation;

- the probability of finding any particle size in the product was considered equal to the average size distribution.

From both considerations, by multiplying the passage probability of each fragment size through the $19 \mathrm{~mm}$ screen with the average retained percentage of the size class, and using the law of total probability, the probability of all classes pass through the upper specification screen was added to the results. In summary, the percentage of passing the $19.0 \mathrm{~mm}$ screen was determined with the following the equation:

$$
\mathrm{p}(\text { passage })=\sum_{k} \mathrm{p}\left(\text { passage } / \mathrm{d}_{\mathrm{k}}\right) \mathrm{p}\left(\mathrm{d}_{\mathrm{k}}\right)
$$

Where $\boldsymbol{k}$ corresponds to any size class.

The number of presentations $\boldsymbol{n}$ that is needed for obtaining a propor-

\section{Results and discussion}

The relative error variances are presented at Table 4. As the calculated

Table 4

Relative Error Variances.

The lower limit of the confidence interval for the percentage of material finer than $19.0 \mathrm{~mm}$ was determined from the variance of the sieving test error shown in Table 4. Using an tion corresponding to that of the lower limit of the confidence interval was determined from an iterative calculation method using the goal seek function in Excel. values are close to each other, there is a both products. standardized experimental condition for

\begin{tabular}{c|c|c|c} 
Products & $\mathrm{s}^{2}(\mathrm{GEE})$ & $\mathrm{s}^{2}(\mathrm{TAE})$ & $\mathrm{s}^{2}(\mathrm{GEE})$ \\
\hline HTV & 0.066 & 0.036 & 0.066 \\
\hline HTP & 0.056 & 0.026 & 0.056 \\
\hline
\end{tabular}

iterative method of calculation, the number of presentations needed for the percentage of materials finer than $19.0 \mathrm{~mm}$ equal to those of the lower limit of the confidence interval was identified. The results were up to 153 presentations for HTV to the sieve mesh (wire thickness: $3.0 \mathrm{~mm}$ ) and up to 121 presentations for HTP, as presented in Tables 5 and 6.
Table 5

Estimation of the number

\begin{tabular}{|c|c|c|c|}
\hline $\begin{array}{c}d \text { size diameter } \\
{[\mathrm{mm}]}\end{array}$ & $\begin{array}{l}\text { Probability of } \\
\text { passage of the } d \\
\text { fragment through } \\
\text { the } 19 \mathrm{~mm} \text { screen } \\
\text { with a single pre- } \\
\text { sentation }\end{array}$ & $\begin{array}{c}\text { Probability of passage of } \\
\text { the } d \text { fragment through the } \\
19 \mathrm{~mm} \text { screen with } \\
\mathrm{n}=121 \text { presentations }\end{array}$ & $\begin{array}{c}\text { Probabilities of } \\
\text { having the grain } \\
\text { size } d \text { in the prod- } \\
\text { uct HTP }\end{array}$ \\
\hline 19.0 & $0.00 \%$ & $0.00 \%$ & $1.33 \%$ \\
\hline 16.0 & $1.86 \%$ & $89.68 \%$ & $4.01 \%$ \\
\hline 12.5 & $8.73 \%$ & $100.00 \%$ & $29.08 \%$ \\
\hline 10.0 & $16.74 \%$ & $100.00 \%$ & $36.25 \%$ \\
\hline 8.0 & $25.00 \%$ & $100.00 \%$ & $12.05 \%$ \\
\hline 6.3 & $33.32 \%$ & $100.00 \%$ & $5.50 \%$ \\
\hline Finer than $6.3 \mathrm{~mm}$ & $51.91 \%$ & $100.00 \%$ & $11.79 \%$ \\
\hline \multicolumn{4}{|c|}{ Percentage of particles finer than $19 \mathrm{~mm}: 98.25 \%$} \\
\hline
\end{tabular}
of presentations for the product HTP. 


\begin{tabular}{c|c|c|c}
\hline $\begin{array}{c}d \text { size diameter } \\
{[\mathrm{mm}]}\end{array}$ & $\begin{array}{c}\text { Probability of pas- } \\
\text { sage of the } d \text { fragment } \\
\text { through the } 19 \mathrm{~mm} \\
\text { screen with a single } \\
\text { presentation }\end{array}$ & $\begin{array}{c}\text { Probability of passage of } \\
\text { the } d \text { fragment through the } \\
19 \mathrm{~mm} \text { screen with } \mathrm{n}=153 \\
\text { presentations }\end{array}$ & $\begin{array}{c}\text { Probabilities of } \\
\text { having the grain } \\
\text { size } \begin{array}{c}\text { in the prod- } \\
\text { uct HTV }\end{array}\end{array}$ \\
\hline 19.0 & $0.00 \%$ & $0.00 \%$ & $1.48 \%$ \\
\hline 16.0 & $1.86 \%$ & $94.34 \%$ & $9.29 \%$ \\
\hline 12.5 & $16.74 \%$ & $100.00 \%$ & $26.02 \%$ \\
\hline 8.0 & $25.00 \%$ & $100.00 \%$ & $24.28 \%$ \\
\hline 6.3 & $33.32 \%$ & $100.00 \%$ & $19.30 \%$ \\
\hline Finer than 6.3 & $51.91 \%$ & $100.00 \%$ & $8.98 \%$ \\
\hline $\mathrm{mm}$. & & $100.00 \%$ & \\
\hline
\end{tabular}

Percentage of particles finer than 19 mm: $97.97 \%$

Although there are more finer particles at HTP in comparison to HTV, its size distribution where there is a larger quantity of fine fragments with a higher probability of passing through the $19 \mathrm{~mm}$ testing screen in comparison to the HTV, implies in less presentations required overall.

The effectiveness of the operating frequency $(\boldsymbol{y})$ to obtain the lower limit of the confidence interval was approximately 0.02 . This result indicates a great deviation from the optimum condition for effectiveness, $y=1$, wherein the particle presents itself isolated for screening. This indicates that the assay was

Where $\boldsymbol{A}$ is the effective sieving area (in square meters) and $\boldsymbol{x}$ is the mesh aperture (in meter). Note that, for $\boldsymbol{x}=19.0 \mathrm{~mm}$ and $\boldsymbol{A}=0.25 \mathrm{~m}^{2}$ the maximum allowable charge would be: $\boldsymbol{m}_{\max }=11.88 \mathrm{~kg}$.

\section{Conclusion}

The technique adapted for estimating the variance of the sieving test error has shown the standardized condition for characterization of the tested products. Therefore, this could be a useful tool to ensure good sample quality.

The method developed to identify the effectiveness of operating frequency conducted with the testing screen full of retained material or that the procedure time was longer than was really needed. As there is a low percentage of particles in the two products that are larger than $19.0 \mathrm{~mm}$, about $1 \%$, the passage of all fragments over that screen occurs in a much shorter time than 5 minutes. If only the information about $19 \mathrm{~mm}$ screen was needed, the proper thing to be done would be a reduction of the time assay to 6 seconds.

As far as the sieving time is concerned, it is important to note that, although 5 minutes would definitely not be enough time for good sieving

$$
\frac{m_{\max }}{A}=2,502.0 \times x
$$

However, it should be borne in mind that coarse aggregate's bulk density (typically 1.7) falls below that of iron ore concentrates (typically 2.7). Using the ratio of such figures of density as the scaling $y$ for the sieving test has shown that the usual sieving operation is largely within the range of safety, since the minimum duration value calculated is smaller than that practiced in routine tests for the bulk material under study. The Authors think that continuity of this study is appropriate to extend the analysis of the sieving
Table 6

Estimation of the number of presentations for the product HTV.

efficiency in a conventional sieve test, in the present case, a majority of the fractions are clearly coarse classes (between 6 and $19 \mathrm{~mm}$ ) as well as the control mesh $(19 \mathrm{~mm})$.

On the other hand, some remarks on the amount of particulate material for sieving are also appropriate. After linear regression of data from the Washington State Department of Transportation (2017) on sieve analysis of aggregates, one can express the maximum mass (in $\mathrm{kg}$ ) per square meter of sieve surface (with correlation coefficient $\left.\boldsymbol{R}^{2}=0.999998\right)$ according to:

factor, it results in a maximum of about $19.0 \mathrm{~kg}$. Thus, also under this criterion, the volumetric limit has not been exceeded after all, keeping the validity of the conclusions herein. coefficient of effectiveness for the entire set of work screens. Additionally, the application of a more elaborate probabilistic model (like the one from Mogensen, 1965) should lead to more realistic values; provided that a little slip in the deduction of Mogensen's final mathematical expression is repaired. 


\section{References}

BORTOLETO, Daniel Armelim et al. The application of sampling theory in bauxite protocols. Rem: Rev. Esc. Minas, Ouro Preto, v. 67, n. 2, p. 215-220, June 2014. Available from <http://www.scielo.br/scielo.php?script=sci_arttext\&pid $=$ S0370-44672014000200014 \&lng=en\&nrm=iso $>$. Access on 26 Feb. 2018. http://dx.doi.org/10.1590/S0370-44672014000200014.

CARVALHO, Simão Célio de; LUZ, José Aurélio Medeiros da. Modelamento matemático de peneiramento vibratório (Parte 2): simulação. Rem: Rev. Esc. Minas, Ouro Preto , v. 58, n. 2, p. 121-125, June 2005. Available from <http://www. scielo.br/scielo.php?script $=$ sci_arttext\& pid=S0370-44672005000200005\& lng=en\&nrm=iso $>$. Access on 26 Feb. 2018. http://dx.doi.org/10.1590/S037044672005000200005.

GAUDIN, A. M. Principles of Mineral Dressing. 1st ed. New York: McGraw-Hill Book Company, 1939. 554 p.

GRIGORIEFF, A.; COSTA, J. F.; KOPPE, J. Quantifying the influence of grain top size and mass on a sample preparation protocol. Chemometrics and Intelligent Laboratory Systems, Amsterdam, v. 74, n.1, p. 201-207, 2004.

GY, P. M. Sampling of Particulate Material: Theory and Practice. 1st ed. Amsterdam: Elsevier, 1979. 43 p.

GY, P. M. Sampling of Heterogeneous and Dynamic Material Systems: 1st ed. Theories of Heterogeneity, Sampling and Homogenizing. Amsterdam: Elsevier, 1992. $652 \mathrm{p}$.

GY, P. M. Sampling of discrete materials: a new introduction to the theory of sampling I. Chemometrics and Intelligent Laboratory Systems, Amsterdam, v. 74, p. 7-24, 2004.

ISO. 3082. Iron ores - Sampling and sample preparation procedures. Geneva: ISO, 2017. $83 \mathrm{p}$.

MINKKINEN, P. Practical applications of sampling theory. Chemometrics and Intelligent Laboratory Systems. Amsterdam, v. 74, n.1, p. 85-94, 2004.

MOGENSEN, F. A New Screening Method of Screening Granular Materials. The Quarry Managers' Journal, p. 409-414. Oct., 1965.

MONTGOMERY, D.C.; RUNGER, G.C. Applied Statistics and Probability for Engineers. 5th edition. Phoenix: John Wiley \& Sons, 2011. 768 p.

PITARD, F. F. Pierre Gy's Sampling Theory and Sampling Practice. 2nd edition. New York: CRC Press, 1993. 488 p.

WASHINGTON STATE DEPARTMENT OF TRANSPORTATION. Sieve Analysis of Fine and Coarse Aggregates. In: WASHINGTON STATE DEPARTMENT OF TRANSPORTATION (Ed.). Materials Manual M 46-01.27 T 11. Olympia: WSDOT, 2017. p. 1-14.

Received: 16 January 2015 - Accepted: 21 February 2018. 